Conclusion: SpA is an independent CVS risk factor. Anti-TNF drugs were associated with a reduced CVS risk in these patients.

REFERENCES:

[1] Crowson CS, Liao KP, Davis JM, 3rd, Solomon DH, Matteson EL, Knutson $\mathrm{KL}$, et al. Rheumatoid arthritis and cardiovascular disease. Am Heart J. 2013;166(4):622-8 e1.

[2] Verhoeven F, Prati C, Demougeot C, Wendling D. Cardiovascular risk in psoriatic arthritis, a narrative review. Joint Bone Spine. 2020;87(5):413-8.

[3] Liew JW, Ramiro S, Gensler LS. Cardiovascular morbidity and mortality in ankylosing spondylitis and psoriatic arthritis. Best Pract Res Clin Rheumatol. 2018;32(3):369-89.

[4] Molto A, Etcheto A, van der Heijde D, Landewe R, van den Bosch F, Bautista Molano W, et al. Prevalence of comorbidities and evaluation of their screening in spondyloarthritis: results of the international cross-sectional ASAS-COMOSPA study. Ann Rheum Dis. 2016;75(6):1016-23.

Disclosure of Interests: None declared.

DOI: 10.1136/annrheumdis-2021-eular.4133

 PATIENTS: A SERIES OF 37 CASES REPORTED IN TOGO}

P. Houzou ${ }^{1}$, V. E. S. Koffi-Tessio², S. Oniankitan ${ }^{3}$, K. Kakpovi ${ }^{1}$, E. Fianyo ${ }^{2}$, K. Tagbor ${ }^{2}$, O. Oniankitan ${ }^{2}$, M. Mijiyaw ${ }^{2} .{ }^{1}$ University of Kara, Rheumatology, Kara, Togo; ${ }^{2}$ University of Lomé, Rheumatology, Lomé, Togo; ${ }^{3}$ University of Lomé, Rheumatology, Kara, Togo

Background: Spondyloarthritis (SpA) is generally uncommon in sub-Saharan Africa, in part because of the rarity of HLA-B27 in this region.

Objectives: The aim of our study was to determine the epidemiological, semiological, paraclinical and therapeutic aspects of ankylosing spondylitis in rheumatology in Togo.

Methods: This was a retrospective multicenter descriptive study on the files of patients suffering from ankylosing spondylitis seen in an outpatient setting or hospitalized in one of the four Rheumatology departments of Togo in the period from January 1, 2000 to December 31, 2019. The diagnosis was essentially radio-clinical based on the modified New York criteria.

Results: In 20 years, and out of a population of 35,304 rheumatic patients, we have collected 37 cases of ankylosing spondylitis, meaning a hospital frequency of $0.10 \%$ and an annual frequency of 1.85 cases. There was clearly a male predominance with an $\mathrm{M} / \mathrm{F}$ ratio of 4.28 . The onset of the disease was on average of $29.62 \pm 10.27$ years and the diagnosis delay on average of $9.45 \pm 9.20$ years. The clinic was dominated by spinal pain in the form of chronic inflammatory cervical-dorsal-lumbar pain $(41.2 \%)$ or lumbar pain $(29.4 \%)$. Common joint injuries were those of the knees $(57.69 \%)$, ankles $(26.9 \%)$ and shoulders $(23.1 \%)$. The most frequent extra-articular manifestations were ocular with conjunctivitis $(62.5 \%)$ and uveitis $(37.5 \%)$. Due to the delayed diagnosis, significant spinal deformities including hypercyphosis, straightness and ankylosis were found; the radiography of the spine objectified syndesmophytes $(50.0 \%)$ with ankyloses and the bamboo column (23.5\%) and that of the pelvis objectified sacroiliitis at stage $3(54.6 \%)$ and at stage $4(27.3 \%)$. The HLA B27 antigen was positive in $10.8 \%$ of cases. NSAIDs and sulfasalazine were the most commonly used drugs in management, respectively in $94.3 \%$ of symptomatic treatment and $92.6 \%$ of background therapy.

Conclusion: Ankylosing spondylitis is relatively rare in Togo, affecting more men and young adults. There are no clinical or paraclinical particularity. The delay in diagnosis reflects the importance of the radiological signs. Treatment is mainly done by NSAIDs and DMRADs in particular sulfasalazine, due to their accessibility.

REFERENCES:

[1] Dean LE, Jones GT, MacDonald AG, Downham C, Sturrock RD, Macfarlane GJ. Global Prevalence of Ankylosing Spondylitis. Rheumatology (Oxford). 2014;53:650-7.

[2] Zabsonre TWJ, Sawadogo SA, Kabore F, Ilboudo A, Sougue C, Zongo E, et al. Ankylosing Spondylitis in Sub-Saharan Africa: A Series of 48 Cases Reported in Burkina Faso (West Africa). Open J Rheumatol Autoimmune Dis. 2018;8:87-92.

[3] Mijiyawa M. Ankylosing Spondylitis in Togolese Patients. Med Trop. 1993;53:185-9.

Disclosure of Interests: None declared.

DOI: 10.1136/annrheumdis-2021-eular.4199

\section{POS1017 CARDIOVASCULAR RISK IN DIFFERENT CLINICAL VARIANTS OF SPONDYLOARTHRITIS}

A. Dadalova ${ }^{1}$, E. Vasilenko ${ }^{1}$, R. Samigullina ${ }^{1}$, V. Mazurov ${ }^{1} .{ }^{1}$ North-Western State Medical University named after I.I. Mechnikov, Department of Therapy,
Rheumatology, Examination of Temporary Disability and Quality of Medical Care named after E.E.Eichwald, St. Petersburg, Russian Federation

Background: Numerous studies have shown that the life expectancy of patients with spondyloarthritis (SPA) is, on average, 5-7 years less compared to the population, and the overall mortality rate is 1.6-1.9 times higher than the population, while mortality from cardiovascular disease increases by $20-40 \%$.

Objectives: of the current study were to assess the cardiovascular risk in pts with with ankylosing spondylitis, psoriatic arthritis and psoriatic spondyloarthritis and to compare different cardiovascular risk scales in these pts.

Methods: The study included 54 patients with SpA aged 45 to 65 years. The patients were divided into 3 groups: patients with ankylosing spondylitis (AS) who meet the modified New York criteria for AS (1984) $(n=14)$, patients with psoriatic arthritis (PsA) who meet the CASPAR criteria (Classification criteria of Psoriatic Arthritis, 2006) $(n=18)$ and patients with psoriatic spondyloarthritis (PsSpA) meeting the modified New York criteria for AS and CASPAR criteria for PsA $(n=22)$.

The average age in the AS group was $55.5 \pm 6.43$ years, in the PSA group -57.4 \pm 5.76 years, in the PsSpA group $-55.0 \pm 6.45$ years. Men made up $64.3 \%$ in the AC group, $50 \%$ in the PsA group, and $49 \%$ in the PsSpA group.

Three indices of cardiovascular risk evaluation (Systematic COronary Risk Evaluation (SCORE) with increasing coefficient 1.5 for inflammatory diseases Reynolds Risk Score (RRS), and the third modification of QRESEARCH Cardiovascular Risk Algorithm (QRISK3) were calculated.

After the numerical assessment of the indicators, each patient was graded in the degree of CVR with the allocation of low, medium, high and very high degree. To stratify the degrees, an estimate of the total risk on the SCORE scale was used: with a value of less than $1 \%$, the risk was considered low, from> $1 \%$ to $5 \%$ medium or moderately increased, from $>5 \%$ to $10 \%$ - high, and $>10 \%$ - very high Results: The values of the indices were in the AS group SCORE $-3,05 \pm 2,41 \%$, RRS - 5,05 $\pm 2,67 \%$, QRISK3 - 6,68 $\pm 3,11 \%$, in pts with PSA SCORE $4,11 \pm 2,22 \%$, RRS $-5.72 \pm 2.46 \%$, QRISK3 $-7.25 \pm 2.51 \%$ and in pts with PsSpA SCORE $-4.78 \pm 2.65 \%$, RRS $-6.35 \pm 2.34 \%$, QRISK3 $-8.02 \pm 3.25 \%$.

Table 1. The number of pts corresponding to different degrees of risk depending on the used CVD risk assessment scale, $n=54$

\begin{tabular}{lccc}
\hline Degrees of risk & SCORE & RRS & QRISK3 \\
\hline Low & 9 & 2 & 0 \\
Medium & 32 & 26 & 16 \\
High & 12 & 23 & 28 \\
Very high & 1 & 3 & 10 \\
\hline
\end{tabular}

When assessing CVR using various risk assessment scales (RRS, QRISK3, SCORE), the highest values were obtained in the PsSpA group.

When comparing the results obtained, it was found that the majority of the surveyed belonging to a low degree of CVR according to SCORE ( 9 people), when evaluated using other scales, fell into the group of medium or high risk. The assessment of the risks of 10-year significant cardiovascular events in patients with SPA using the SCORE index does not coincide with the QRISK3 index data in $70.4 \%$ of cases, with the RRS data - in $42.6 \%$ of cases, and the SCORE index shows lower values of the expected risk. The highest values were obtained when assessing CVR using the scale QRISK3.

Conclusion: The highest CVR values were obtained in the PsSpA group using various risk assessment scales (RRS, QRISK3, SCORE). There was a discrepancy in the severity of CVR calculated using different rating scales in SpA patients. The largest values were obtained when using the scale QRISK3, and the smallest when calculating the CVR using the scale SCORE.

\section{REFERENCES:}

[1] Horreau C, Pouplard C, Brenaut E, Barnetche T, Misery L, Cribier B, et al. Cardiovascular morbidity and mortality in psoriasis and psoriatic arthritis: a systematic literature review. J Eur Acad Dermatol Venereol 2013;27 Suppl 3:12-29.

[2] Bengtsson K, Forsblad-d'Elia H, Lie E, et al. Are ankylosing spondylitis, psoriatic arthritis and undifferentiated spondyloarthritis associated with an increased risk of cardiovascular events? A prospective nationwide population-based cohort study. Arthritis Res Ther. 2017 May 18;19(1):102. doi: 10.1186/s13075-017-1315-z

Disclosure of Interests: None declared.

DOI: 10.1136/annrheumdis-2021-eular.4209

\section{POS1018 \\ IMPORTANCE OF LATERAL SPINE VIEW IN DXA BONE DENSITOMETRY IN PATIENTS WITH SPONDYLOARTHRITIS}

S. Miri ${ }^{1}$, H. Ferjani ${ }^{1}$, K. Maatallah ${ }^{1}$, A. Kasraoui ${ }^{1}$, D. Kaffel ${ }^{1}$, W. Hamdi ${ }^{1}$ ${ }^{1}$ Mohamed Kassab Institute of Orthopedics, Rhumatology, Manouba, Tunisia 